\title{
Verification of clinically diagnosed cases during malaria elimination programme in Guizhou Province of China
}

Jianhai Yin ${ }^{1,2,3}$, Zhigui Xia ${ }^{1,2,3^{*}}$, He Yan ${ }^{1,2,3}$, Yuting Huang ${ }^{4}$, Lidan Lư ${ }^{4}$, Yan Geng ${ }^{4}$, Ning Xiao ${ }^{1,2,3}$, Jianjun Xu ${ }^{4}$, Ping $\mathrm{He}^{4}$ and Shuisen Zhou ${ }^{1,2,3^{*}}$

\begin{abstract}
Background: China is implementing a National Malaria Elimination Programme. A high proportion of clinically diagnosed malaria cases is reported in some provinces of China. In order to understand the exact situation and make clear the nature of these patients, it is of much importance to make case verifications, particularly from the pathogenic perspective.
\end{abstract}

Methods: Guizhou Province was targeted because of its high proportion of clinically diagnosed malaria cases. After random selection of around 10\% of malaria cases from 1 May 2011 to 30 April 2012, reported through the national web-based case reporting system from this province, field verifications were made on 14-17 May 2012 as follows. Firstly, the reported information of each case was rechecked with the onsite case registrations and investigation forms, and an in-depth interview was conducted with each patient. Secondly, the patient's blood smears kept by local CDC were cross-checked microscopically by a national experienced microscopist. Thirdly, two kinds of polymerase chain reaction (PCRs). including Tag-primer nested/multiplex PCR (UT-PCR) based on cytochrome oxidase gene ( $\operatorname{cox} I)$ and nested PCR based on 18s rRNA gene were performed simultaneously using local CDC kept filter paper of dry blood samples to identify the Plasmodium spp.

Results: Twelve out of 152 malaria cases were selected, including nine clinically diagnosed malaria cases, two confirmed falciparum malaria cases and one confirmed vivax malaria case. The original case documents on the site were completely in conformity with their reported data, and all the patients recalled their malaria symptoms and being cured only after consuming the corresponding anti-malarial drugs. Moreover, the re-examination results of microscopy and PCR were exactly in agreement with the original tests.

Discussion: No inconsistent results were found against the reported case information in the present study and the reasons for clinically diagnosed patients remains unclear. Uniform and standardized sample collection and processing should be trained among clinicians, more sensitive and specific techniques should be explored to used in malaria diagnosis. A further study is needed in order to be more observationally focussed rather than retrospective.

Keywords: Case verification, Malaria elimination, UT-PCR, Nested PCR, Guizhou Province

\footnotetext{
*Correspondence: xzg1976@yahoo.com.cn; ccdczss@sh163.net

${ }^{1}$ National Institute of Parasitic Diseases, Chinese Centre for Disease Control

and Prevention (NIPD, China CDC), Shanghai 200025, China

${ }^{2}$ Key Laboratory of Parasite and Vector Biology, MOH, China, Shanghai

200025, China

Full list of author information is available at the end of the article
} 


\section{Background}

As the lowest malaria burden was achieved, in order to protect the public health and respond to global malaria elimination initiative, the Chinese government launched the Action Plan of China Malaria Elimination (2010-2020) [1] in 2010 with an overall goal:- by 2015, local transmission of malaria should be eliminated except for partial border areas in Yunnan Province; and by 2020, malaria elimination should be achieved nationwide. In 2011, the malaria cases reported was reduced about $43.0 \%$ compared 2010, and accordingly the annual incidence was reduced to $0.0334 / 10,000$. Furthermore, there were $56.7 \%$ vivax malaria and $40.2 \%$ falciparum malaria among the cases with laboratory confirmation [2].

The definition of malaria case in an elimination programme is very different from a control programme. In an elimination programme, it is defined as a person in whom, regardless of the presence or absence of clinical symptoms, malaria parasites have been confirmed by quality controlled laboratory diagnosis [3,4]. In the $A c$ tion Plan of China Malaria Elimination (2010-2020) [1] as well as the Technical Scheme of China Malaria Elimination (2011 Edition) [5], it is the requirement that by 2012 the laboratory testing rate of malaria cases should reach $100 \%$ and the rate of laboratory confirmation should reach $75 \%$. However, a number of clinically diagnosed or unconfirmed cases still exists. According to the national web-based case reporting system, it was noted that the proportion of clinically diagnosed malaria cases were over $25 \%$ in about one-third (10/34); Provinces/ Municipalities/Autonomous Regions in China; and almost reached $90 \%$ in the key malaria-prevalent Province of Guizhou.

As every one of the malaria patients should be laboratory confirmed during elimination stage, it is necessary to make case verifications, particularly from the pathogenic perspective in order to understand the exact situation and make clear the nature of these clinically diagnosed patients.

\section{Methods}

\section{Sample enrolment}

Using the national web-based case reporting system, around 10\% malaria cases reported from Guizhou Province during 1 May 2011 to 30 April 2012 were randomly selected into the present study, since the verifications were planned on 14-17 May 2012. All the reported case cards that had patients' basic and diagnostic data were downloaded. All the original case registrations and investigation forms were from on site; and for each case, one slide of blood smears and one filter paper of dried blood spots kept in Guizhou provincial CDC were obtained.

\section{Case document review and case interview}

All the reported information, including the name, gender, age, residence, date of fever onset, date and result of diagnosis, responsible health facility and doctor, etc., were compared manually with the original documents for each targeted patient. Afterwards, household interview with each patient was done in order to verify their existence, as reported.

\section{Ethical clearance}

The study was reviewed and approved by the Ethical Committee of National Institute of Parasitic Diseases, China CDC. All patients provided informed consent before admission into the study.

\section{Microscopy}

Both thin and thick blood smears of each Giemsa-stained slide were qualitatively evaluated and checked for malaria species by an assigned experienced microscopist from NIPD, China CDC, who was blinded to the results. The examination was performed following the WHO standard protocol under a $100 \times$ oil immersion objective [6].

\section{DNA extraction and PCR amplification}

In Guizhou provincial CDC, two different methods for DNA extraction and polymerase chain reaction (PCR) amplification were applied simultaneously by two independent technicians: one from NIPD and one from Guizhou provincial CDC.

For the technician from Guizhou provincial CDC, a piece of $6 \mathrm{~mm}$ diameter dry blood sample containing around $4 \mu \mathrm{l}$ whole blood was put into a $0.5 \mathrm{ml}$ EP tube, then $400 \mu \mathrm{l} \mathrm{PCR}$ buffer $(1 \times)$ was added, and centrifuged at $18,000 \times \mathrm{g}$ for $2 \mathrm{~min}$ after $10 \mathrm{~min}$ standing at room temperature, then $20 \mu \mathrm{l} \mathrm{PCR}$ buffer $(1 \times)$ added again after suspension discarded, and heated at $95^{\circ} \mathrm{C}$ for $5 \mathrm{~min}$, centrifuged at $18,000 \times \mathrm{g}$ for $1 \mathrm{~min}$, and the suspension was the template stored at $4^{\circ} \mathrm{C}$ until use; a method of Tag-primer nested/multiplex PCR (UT-PCR) which can detect one parasite/ $\mu$ l was applied, the target gene was the cytochrome oxidase gene ( $\operatorname{cox} I)$ which is located in mitochondrion, and seven primers were designed for this amplification [7].

However, for the technician from NIPD, DNA was extracted from dry blood sample using the QIAamp DNA Mini Kit (Qiagen), in accordance with the manufacturer's instruction. Qualitative detection of Plasmodium spp. through nested PCR amplification based on multicopy 18 s rRNA gene in a reaction of $20 \mu$ as described elsewhere [8] with some minor adjustments. Moreover, two positive controls consisting of Plasmodium vivax DNA and Plasmodium falciparum DNA separately, and a negative control consisting of DNA extracted from malaria-negative blood and a blank control consisting of 


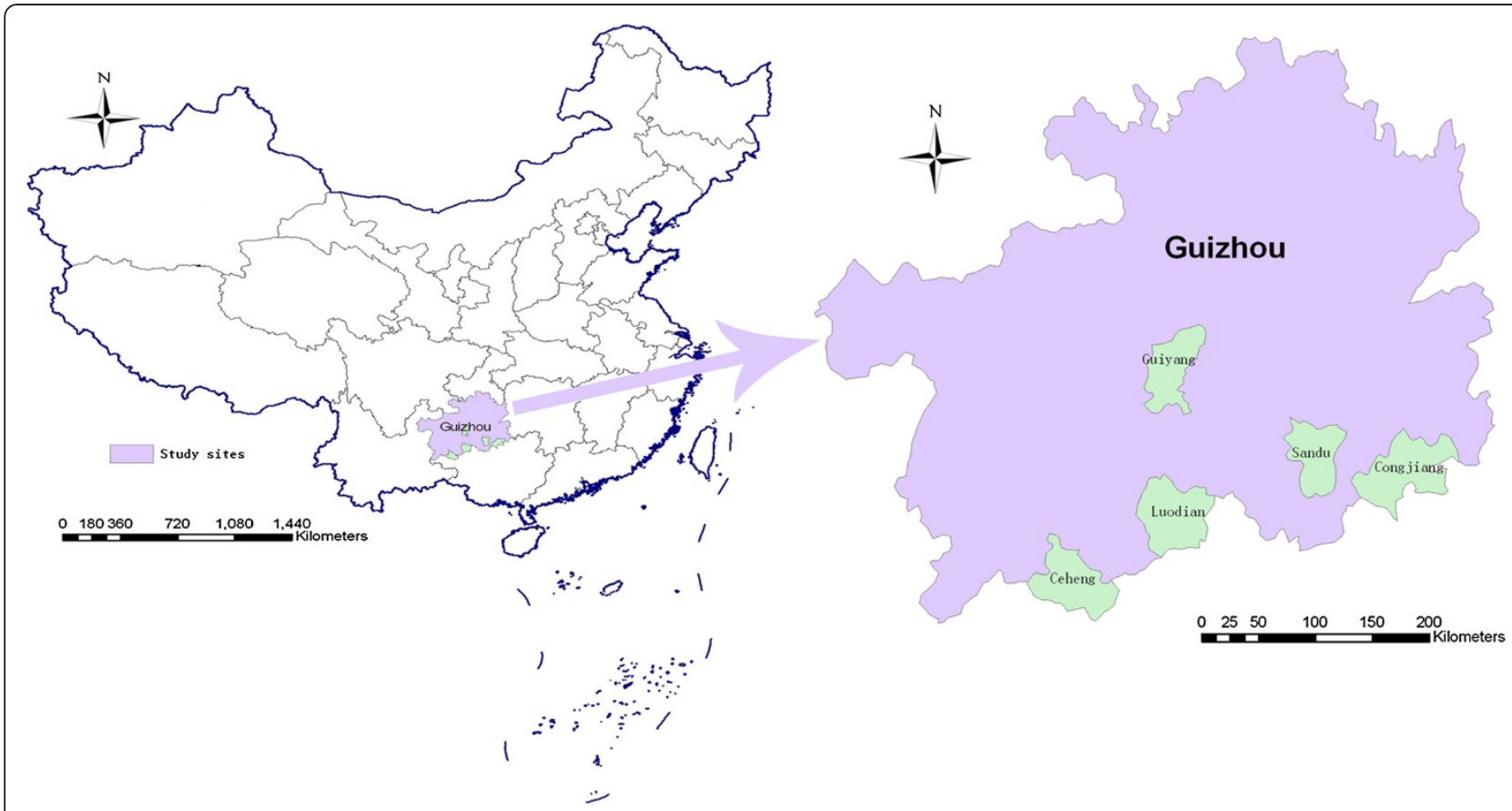

Figure 1 The target province and selected samples' distribution.

double-distilled water, were included in each PCR run. In addition, amplified regions were separated using $2 \%$ agarose gel electrophoresis and visualized following GelRed staining.

\section{Results}

Target province and selected samples

Guizhou Province was targeted because of its high proportion of clinically diagnosed malaria cases. From 1 May 2011 to 30 April 2012, 86.18\% (131/152) reported malaria cases from this province were diagnosed as "clinical cases" according to the clinical symptoms related to malaria despite negative results of laboratory test through microscopy.

Twelve out of 152 malaria cases were selected into the present study. Two confirmed imported falciparum malaria cases were from Guiyang City (code: M2, M3); nine clinically diagnosed local malaria cases were from Sandu County (code: SD1, SD2, SD6, SD8, SD11, SD19), Luodian County (code: LD5, LD12) and Ceheng County (code: $\mathrm{CH} 5$ ); and one confirmed local vivax malaria case from Congjiang County (code: CJ3) (Figure 1 and Table 1).

Table 1 Basic data and verification results of the study samples

\begin{tabular}{|c|c|c|c|c|c|}
\hline Code & Gender & Age (y) & Onset time & Original diagnosis & Plasmodium spp. verified \\
\hline$\overline{M 2}$ & Male & 55 & June 2011 & Imported falciparum malaria* & P. falciparum \\
\hline M3 & Male & 48 & August 2011 & Imported falciparum malaria* & P. falciparum \\
\hline SD1 & Male & 69 & May 2011 & Local clinical case & Negative \\
\hline SD2 & Male & 55 & June 2011 & Local clinical case & Negative \\
\hline SD6 & Male & 16 & August 2011 & Local clinical case & Negative \\
\hline SD8 & Male & 10 & August 2011 & Local clinical case & Negative \\
\hline SD11 & Female & 25 & August 2011 & Local clinical case & Negative \\
\hline SD19 & Male & 38 & September 2011 & Local clinical case & Negative \\
\hline LD5 & Male & 53 & July 2011 & Local clinical case & Negative \\
\hline LD12 & Male & 65 & August 2011 & Local clinical case & Negative \\
\hline $\mathrm{CJ} 3$ & Female & 36 & July 2011 & Local vivax malaria & P. vivax \\
\hline $\mathrm{CH} 5$ & Female & 35 & April 2011 & Local clinical case & Negative \\
\hline
\end{tabular}




\section{Case verifications}

The original case documents on the site were completely in conformity with their reported data, and all the patients recalled their malaria symptoms and being cured only after consuming the corresponding anti-malarial drugs according to national guidelines [9].

Moreover, the re-examination results of microscopy and PCRs were in agreement with the original tests. The results of slides were identical to each other, tested by two different microscopists from Guizhou provincial CDC and NIPD respectively. Besides, the result of gel electrophoresis showed that cox $I$ and18s rRNA genes were successfully amplified as a result of $P$. falciparum with the band around $200 \mathrm{bp}$ (18s rRNA) and $620 \mathrm{bp}$ $(\operatorname{cox} I)$ from two Guiyang City samples and the $P$. falciparum positive control by two methods mentioned above separately; and one sample from Congjiang County and the $P$. vivax positive control was detected as $P$. vivax around $120 \mathrm{bp}$ (18s rRNA) and $220 \mathrm{bp}(\operatorname{cox} I)$ based on these two target genes; all the rest of the samples were negative.

\section{Discussion}

Malaria has been a major public health problem historically in China, and China has made an impact on malaria disease burden with successful large-scale malaria control activities nationwide [10,11] and is now entering an age of malaria elimination since the Action Plan of China Malaria Elimination (2010-2020) was presented. In recent years, the number of malaria cases in China has been declining, with a yearly average of $46.09 \%$ [12]; most areas are free of endemic malaria, and some are in the low prevalence, this includes Guizhou, a western province bordering with Yunnan, Sichuan, Chongqing, Guangxi and Hunan Provinces/Municipalities/Autonomous Regions [13].

Generally in low transmission areas, due to the existence of asymptomatic and low parasitaemia malaria patients, prompt and effective detection/diagnosis has been a problem. Although light microscopy can characterize and quantify Plasmodium parasites rapidly and is the operational gold standard in control and elimination settings [14,15], the asymptomatic and micro-parasitaemia infections are beyond its detective capability [16-18]. As a result, PCR has got to be recognized as the reliable and sensitive method for malaria diagnosis, particularly to detect the submicroscopy Plasmodium infection, and it can identify morphologically similar species [19-21]. The methods of detecting circulating parasites by demonstrating parasite DNA through PCR assays based on 18s rRNA gene represent the overall gold standard of malaria diagnostics [22].

However in Guizhou Province, the problem is not just the asymptomatic and low-parasitaemia infection under low malaria transmission, but also that most malaria cases were reported having clinical malaria symptoms and susceptible to the anti-malarial drugs, but with no laboratory evidence of Plasmodium infection. In view of uncertainty in the real malaria burden of Guizhou Province, this study using retrospective design and comprehensive crosscheck approaches of case document review, case interview, microscopy and the more sensitive PCRs, attempted to understand the real malaria infections including both the asymptomatic and symptomatic, and tried to identify the differences between the results by light microscopy and PCR in such a context.

In this study, in order to ensure the accuracy of pathogenic confirmation, besides light microscopy, two kinds of PCR were used. One is nested PCR based on 18s rRNA gene, and the other is Tag-primer nested/multiplex PCR (UT-PCR) based on cytochrome oxidase gene ( $\operatorname{cox} I$ ). Nested PCR based on 18s rRNA gene [8] has been widely used in laboratories, clinics and field [23,24] for Plasmodium characterization; it demonstrated that this method was much more efficient although there are limitations. UT-PCR based on cox $I$ gene in this study showed both sensitivity and specificity were higher than 98\% [7], and the detection limit of either P. falciparum or $P$. vivax reached one parasite/ $\mu \mathrm{l}$ [25]. Thus, random sampling, case document review, case interview, blood samples recheck or crosscheck through two PCRs combined with two experienced microscopists, were much more powerful for malaria detection/diagnosis theoretically.

In the present study, all the results from different methods were in good agreement with each other, and no inconsistent results were found against the reported cases information; however, the reason for clinically diagnosed patients remains unclear. It may be attributed to incorrect sampling or the clinically diagnosed patients infected with other pathogen rather than Plasmodium with symptoms similar to malaria, which were also susceptible to anti-malarial drugs. Although malaria diagnosis reference laboratory network has started in China since 2011, and several provincial reference laboratories have been set up in provincial CDC, respectively, it was suggested that clinicians should be trained for uniform and standardized sample collection and processing. Furthermore, it is recommended that more sensitive and specific techniques be used in malaria diagnosis, but no inconsistent results were found in this study.

\section{Competing interest}

The authors declare that they have no competing interests.

\section{Authors' contributions}

JY, ZX and SZ participated in the conception of study design. Case review was carried out by JY, ZX, HY, YG and NX. Case interview and microscopy were carried out by ZX, HY, LL, JX, PH and NX. DNA extraction and PCR amplification were carried out by $J Y$ and $\mathrm{YH}$. Data analysis and manuscript drafting was carried out by JY and ZX with support and contributions from $\mathrm{LL}$ and SZ. All authors have read and approved the final manuscript. 


\section{Acknowledgements}

This work was supported by the National S \& T Major Program (Grant No. 2012ZX10004-220). We wish to thank the staff for malaria in the county CDCs of Guizhou Province.

\section{Author details}

${ }^{1}$ National Institute of Parasitic Diseases, Chinese Centre for Disease Control and Prevention (NIPD, China CDC), Shanghai 200025, China. ${ }^{2}$ Key Laboratory of Parasite and Vector Biology, MOH, China, Shanghai 200025, China. ${ }^{3} \mathrm{WHO}$ Collaborating Centre for Malaria, Schistosomiasis and Filariasis, Shanghai 200025, China. ${ }^{4}$ Guizhou Provincial CDC, Guiyang 550004, China.

Received: 5 December 2012 Accepted: 12 April 2013

Published: 15 April 2013

\section{References}

1. The Ministry of Health of the People's Republic of China: Action Plan of China Malaria Elimination (2010-2020); 2012. Available: http://www.gov.cn/gzdt/att/ att/site1/20100526/001e3741a2cc0d67233801.doc. Accessed 5 Nov 2012.

2. Xia ZG, Yang MN, Zhou SS: [Malaria situation in the People's Republic of China in 2011](in Chinese). Zhongguo Ji Sheng Chong Xue Yu Ji Sheng Chong Bing Za Zhi 2012, 30:419-422.

3. WHO: Malaria elimination - A field manual for low and moderate endemic countries. 20 Avenue Appia, 1211 Geneva 27, Switzerland: WHO Press, World Health Organization; 2007.

4. WHO: Disease surveillance for malaria elimination - an operational manual. 20 Avenue Appia, 1211 Geneva 27, Switzerland: WHO Press, World Health Organization; 2012.

5. Chinese Centre for Disease Control and Prevention: Technical Scheme of China Malaria Elimination (2011 Edition). Available: http://www.chinacdc.cn/jkzt/crb/ nj/jszl_2223/201109/U020110906536170416565.pdf. Accessed 5 Nov 2012.

6. WHO: Basic Malaria Microscopy - Part I. Learner's Guide, second edition. Geneva, Switzerland; 2010. Available: http://www.searo.who.int/LinkFiles/ Malaria_malaria_microscopy_Learners_guide2010.pdf. Accessed 5 Nov 2012.

7. Guo CK, Li XM, Li JH, Mao W, Lin Z, Du JF, Huang TY: [Sensitivity, specificity and stability of the Tag-primer nested/multiplex PCR for malaria diagnosis](in Chinese). Zhongguo Ji Sheng Chong Xue Yu Ji Sheng Chong Bing Za Zhi 2007, 25:213-216.

8. Snounou G, Viriyakosol S, Zhu XP, Jarra W, Pinheiro L, do Rosario VE, Thaithong S, Brown KN: High sensitivity of detection of human malaria parasites by the use of nested polymerase chain reaction. Mol Biochem Parasitol 1993, 61:315-320.

9. The Ministry of Health of the People's Republic of China: The Guideline and Scheme for the Use of Antimalarial Drugs in China; 2012. Available: http:// www.moh.gov.cn/publicfiles/business/htmlfiles/mohjbyfkzj/s3594/200907/ 41610.htm. Accessed 5 Nov 2012

10. Diouf G, Kpanyen PN, Tokpa AF, Nie S: Changing landscape of malaria in China: progress and feasibility of malaria elimination. Asia Pacific J: Public Health; 2011.

11. $\mathrm{Xu} \mathrm{J,} \mathrm{Liu} \mathrm{H:} \mathrm{The} \mathrm{challenges} \mathrm{of} \mathrm{malaria} \mathrm{elimination} \mathrm{in} \mathrm{Yunnan} \mathrm{Province,}$ the People's Republic of China. Southeast Asian J Trop Med Public Health 2012, 43:819-824.

12. Zhou XN: [Status and future focus of the national control program on parasitic diseases](in Chinese). Chinese J Schistosomiasis Control 2011, 23:473-475.

13. Zhou SS, Wang Y, Li Y: [Malaria situation in the People's Republic of China in 2010](in Chinese). Zhongguo Ji Sheng Chong Xue Yu Ji Sheng Chong Bing Za Zhi 2011, 29:401-403.

14. Ohrt C, Purnomo, Sutamihardja MA, Tang D, Kain KC: Impact of microscopy error on estimates of protective efficacy in malaria-prevention trials. $J$ Infect Dis 2002, 186:540-546.

15. Ohrt C, Obare P, Nanakorn A, Adhiambo C, Awuondo K, O'Meara WP, Remich S, Martin K, Cook E, Chretien JP, Lucas C, Osoga J, McEvoy P, Owaga ML, Odera JS, Ogutu B: Establishing a malaria diagnostics centre of excellence in Kisumu, Kenya. Malar J 2007, 6:79.

16. Kitua A, Ogundahunsi $\mathrm{O}$, Lines J, Mgone C: Conquering malaria: enhancing the impact of effective interventions towards elimination in the diverse and changing epidemiology. J Glob Infect Dis 2011, 3:161-165.

17. Price RN, Nosten F, Luxemburger C, ter Kuile FO, Paiphun L, Chongsuphajaisiddhi T, White NJ: Effects of artemisinin derivatives on malaria transmissibility. Lancet 1996, 347:1654-1658.
18. Stresman G, Kobayashi T, Kamanga A, Thuma PE, Mharakurwa S, Moss WJ, Shiff C: Malaria research challenges in low prevalence settings. Malar J 2012, 11:353.

19. Humar A, Ohrt C, Harrington MA, Pillai D, Kain KC: Parasight $F$ test compared with the polymerase chain reaction and microscopy for the diagnosis of Plasmodium falciparum malaria in travelers. AmJTrop Med Hyg 1997, 56:44-48.

20. Zoghi S, Mehrizi AA, Raeisi A, Haghdoost AA, Turki H, Safari R, Kahanali AA, Zakeri S: Survey for asymptomatic malaria cases in low transmission settings of Iran under elimination programme. Malar J 2012, 11:126.

21. Johnston SP, Pieniazek NJ, Xayavong MV, Slemenda SB, Wilkins PP, da Silva $\mathrm{AJ}$ : PCR as a confirmatory technique for laboratory diagnosis of malaria. J Clin Microbiol 2006, 44:1087-1089.

22. Kamau E, Tolbert LS, Kortepeter L, Pratt M, Nyakoe N, Muringo L, Ogutu B, Waitumbi JN, Ockenhouse CF: Development of a highly sensitive genus-specific quantitative reverse transcriptase real-time PCR assay for detection and quantitation of Plasmodium by amplifying RNA and DNA of the 18S rRNA genes. J Clin Microbio/ 2011, 49:2946-2953.

23. Fuehrer HP, Starzengruber P, Swoboda P, Khan WA, Matt J, Ley B, Thriemer K, Haque R, Yunus EB, Hossain SM, Walochnik J, Noedl H: Indigenous Plasmodium ovale malaria in Bangladesh. AmJTrop Med Hyg 2010, 83:75-78.

24. Zakeri S, Najafabadi ST, Zare A, Djadid ND: Detection of malaria parasites by nested PCR in south-eastern, Iran: evidence of highly mixed infections in Chahbahar district. Malar J 2002, 1:2

25. Guo CK, Li XM, Li Z, Wang GZ, Yang YM, Li JH, Jiang ZH, Huang TY: [Primary evaluation on the application of Nested/Multiplex PCR in malaria diagnosis and surveillance](in Chinese). Zhongguo Ji Sheng Chong Xue Yu Ji Sheng Chong Bing Za Zhi 2008, 26:277-280.

doi:10.1186/1475-2875-12-130

Cite this article as: Yin et al:: Verification of clinically diagnosed cases during malaria elimination programme in Guizhou Province of China. Malaria Journal 2013 12:130

\section{Submit your next manuscript to BioMed Central and take full advantage of:}

- Convenient online submission

- Thorough peer review

- No space constraints or color figure charges

- Immediate publication on acceptance

- Inclusion in PubMed, CAS, Scopus and Google Scholar

- Research which is freely available for redistribution

Submit your manuscript at www.biomedcentral.com/submit
C Biomed Central 